\title{
A Descriptive, Multiyear Examination of Positive Behavior Support
}

\author{
Glen Dunlap \\ University of South Florida, glendunlap@sbcglobal.net \\ Edward G. Carr \\ State University of New York, Stony Brook \\ Robert H. Homer \\ University of Oregon \\ Robert L. Koegel \\ University of California - Santa Barbara \\ Wayne Sailor \\ University of Kansas, wsailor@ku.edu
}

See next page for additional authors

Follow this and additional works at: https://ecommons.luc.edu/education_facpubs

Part of the Education Commons

\section{Recommended Citation}

Dunlap, Glen, Edward G. Carr, and et. al. (2010). "A Descriptive, Multiyear Examination of Positive Behavior Support." Behavioral Disorders, 35(4): 259-279.

This Article is brought to you for free and open access by the Faculty Publications and Other Works by Department at Loyola eCommons. It has been accepted for inclusion in Education: School of Education Faculty Publications and Other Works by an authorized administrator of Loyola eCommons. For more information, please contact ecommons@luc.edu.

\section{c) (1) (9)}

This work is licensed under a Creative Commons Attribution-Noncommercial-No Derivative Works 3.0 License. (C) 2010 Council for Children with Behavioral Disorders 


\section{Authors}

Glen Dunlap, Edward G. Carr, Robert H. Homer, Robert L. Koegel, Wayne Sailor, Shelley Clarke, Lynn Kern Koegel, Richard W. Albin, Bobbie J. Vaughn, Darlene Magito McLaughlin, Kim Mullen, Anne W. Todd, J.

Stephen Newton, Joseph Lucyshyn, Peter Griggs, Hank Bohanon, Jeong Hoon Choi, Laurie Vismara, and

Pamelazita Buschbacher 


\title{
A Descriptive, Multiyear Examination of Positive Behavior Support
}

\author{
Glen Dunlap \\ University of South Florida
}

Edward G. Carr

State University of New York at Stony Brook and Developmental

Disabilities Institute

Robert H. Horner

University of Oregon

Robert L. Koegel

University of California at Santa Barbara

Wayne Sailor

University of Kansas

Shelley Clarke

University of South Florida

Lynn Kern Koegel

University of California at Santa Barbara

Richard W. Albin

University of Oregon

Bobbie J. Vaughn

University of South Florida

Darlene Magito McLaughlin

Positive Behavior Support Consulting

Kim Mullen James

Developmental Disabilities Institute

\author{
Anne W. Todd \\ University of Oregon \\ J. Stephen Newton \\ University of Oregon \\ Joseph Lucyshyn \\ University of British Columbia
}




\title{
Peter Griggs \\ University of Kansas
}

\author{
Hank Bohanon \\ Loyola University of Chicago
}

\author{
Jeong Hoon Choi \\ University of Kansas
}

\author{
Laurie Vismara \\ University of California at Davis
}

\author{
Mendy Boettcher Minjarez \\ Stanford University School of Medicine
}

\author{
Pamelazita Buschbacher \\ University of South Florida
}

\author{
Lise Fox \\ University of South Florida
}

\begin{abstract}
A major goal of positive behavior support (PBS) is to produce broad-based, long-term improvements in adaptive behavior; however, the empirical base, at present, is mainly composed of relatively short-term studies carried out in circumscribed contexts. Therefore, a need exists for reliable data that can inform the field regarding the comprehensive lifestyle effects of PBS implementation in natural community contexts over extended periods of time. The current investigation was conducted to provide a descriptive analysis of PBS with diverse participants and broad measurement strategies over multiple years. Using extensive data portfolios for 21 participants, we employed rating scales to quantify changes in key variables from baseline through 2 years of intervention. The data revealed variable levels of intervention integrity, generalized reductions in problem behavior with occasional relapses, and encouraging enhancements across six domains of quality of life. This study represents an initial attempt to understand the processes and outcomes of behavioral support by documenting behavioral patterns across full days, entire years, and all environments. We discuss the need to consider new conceptual and methodological frameworks for further study of efficacious and sustainable behavior support.
\end{abstract}

Positive behavior support (PBS) is an approach for improving quality of life (QOL) and resolving behavior problems (Carr et al., 2002) that has gained considerable empirical support and popularity in recent years (Carr et al., 1999; Dunlap \& Hieneman, 2005; Sailor, Dunlap, Sugai, \& Horner, 2009). Positive behavior support emerged in the mid-1980s as a set of intervention strategies that could be used in all community, home, and school settings to address serious problem behaviors without resorting to painful or stigmatizing procedures. It was designed as a proactive approach through which enhancements of an individual's competencies would lead to an enriched and more satisfying life and, secondarily, to reductions in serious problem behaviors. Positive behavior support evolved from applied behavior analysis and remains affiliated with this core discipline, even though it also draws from other traditions, disciplines, and methods (Dunlap, Carr, Horner, Zarcone, \& Schwartz, 2008). The primary goal of PBS is to improve an individual's QOL by gaining an understanding of the variables that govern an individual's behavior and then using that 
understanding to teach the individual new skills for controlling his or her environment and rearranging the environment so that it is more likely to support desirable, prosocial responding (Bambara \& Kern, 2005; Janney \& Snell, 2008).

The empirical support for PBS has been summarized in a number of publications over the past decade (e.g., Carr, Horner, et al., 1999; Dunlap \& Carr, 2007). In essence, these syntheses demonstrate that (a) the process of functional assessment is useful for identifying the function of and controlling variables for problem behavior and that the results of functional assessment can be used to enhance the efficacy of subsequent interventions, (b) teaching alternative skills is an effective strategy for reducing problem behaviors (e.g., Carr \& Durand, 1985; Halle, Bambara, \& Reichle, 2005), (c) altering antecedent variables on the basis of functional assessment data can rapidly reduce the occurrence of problem behaviors (Luiselli, 2007), and (d) multicomponent PBS interventions, based on functional assessments, have been shown in several investigations to be associated with reductions in problem behaviors and increases in alternative, desirable responding (e.g., Carr, Levin, et al., 1999). The findings just summarized are based on considerable data from numerous investigations. Other elements of PBS practice have less research support but are based on extensive clinical experience, some evaluation data, and occasional experimental or quasi-experimental studies. Such practices include the assessment of contextual variables, the use of person-centered planning, and the manipulation of setting events as a component of intervention (Dunlap \& Carr, 2007).

Although the empirical support for the core components of PBS is acknowledged, many authors have described important limitations in the existing data base (e.g., Dunlap \& Carr, 2007). Perhaps the most conspicuous limitation is that the vast majority of relevant studies have involved observations restricted to relatively short periods of time (e.g., 35 months) and confined to only one or two well-controlled settings. These limitations are understandable given the strictures of research designs, but they are inconsistent with the goal of improving QOL, a construct that pertains to the full breadth of a person's existence, across all settings and hours of the day, and for periods of years, rather than the usual weeks or months of intervention research (Hughes,
Hwang, Kim, Eisenman, \& Killian, 1995; Schalock, 1990).

There have been a few notable exceptions in which PBS interventions have been implemented in a comprehensive manner across extended periods of time (e.g., Lucyshyn et al., 2007). For instance, Feldman, Condillac, Tough, Hunt, and Griffiths (2002) conducted a study with 20 individuals with developmental disabilities who exhibited severe problem behaviors such as self-injury and aggression. They implemented a PBS protocol, including functional assessment and antecedent and reinforcement-based interventions. The authors found significant reductions in problem behavior and increases in replacement skills, and for 14 participants who received follow-up services, they noted improvements for up to 3 years following the initial intervention. In another study, Carr, Levin, et al. (1999) described a detailed assessment strategy and a five-step PBS intervention that they evaluated using an experimental multiple-baseline design with three adults who demonstrated severe behavior problems. The results showed favorable outcomes on dependent variables (e.g., task engagement, problem behavior), with evidence of maintenance for 1.5 to 2.5 years. Importantly, the authors also described changes in the participants' life circumstances such as residential and employment status, and recreational opportunities, as well as the need for follow-up assessments and adjustments to the intervention plans as time passed and external variables influenced the participants' life situations.

The latter observation by Carr, Levin, and colleagues (1999) raises vital points related to the goals of PBS. That is, the ultimate purpose of PBS interventions is to produce or facilitate enduring improvements in QOL. However, the extent to which this might occur is not understood, and very little pertinent research has been conducted. There is a great need to examine the implementation and impact of PBS over extended periods of time to gain a better understanding of long-term effects on problem behavior and QOL. Therefore, the current investigation was conducted in an effort to describe the integrity of PBS implementation by natural implementation agents in natural community settings and the effects of this implementation over a period of 2 full years. The principal research question was, "When the process and procedures of PBS are developed and implemented by teams of 
natural intervention agents in typical community settings in order to benefit participants with histories of chronic, serious problem behaviors, what are the effects on problem behavior and QOL across the full span of a participant's life over an extended period of time (2 years)?" In addition, to supplement information pertaining to this principal question, we obtained information regarding the extent to which PBS was actually implemented as planned over the 2 years of data collection; that is, we examined the issue of sustainability of intervention integrity.

In sum, the purpose of the present investigation was to provide a new model for programmatic research in the field of PBS that can be described in terms of seven integrated characteristics: multicomponent, ecological validity, comprehensiveness, sustainability, longitudinal, multidimensional, and heuristic. Multicomponent refers to the use of a broad array of interventions that include environmental redesign, skill building, and systemic change. Ecological validity refers to the involvement of natural intervention agents in typical community settings. Comprehensiveness refers to addressing behavior issues in all settings relevant to normative living. Sustainability refers to the accurate and consistent implementation of the intervention across protracted periods of time. Longitudinal refers to the evaluation of the effects of intervention implementation across protracted periods of time. Multidimensional refers to the assessment of a broad range of clinically and socially significant outcomes. Heuristic refers to the identification of deficiencies in the intervention approach, evaluative strategy, and outcome success, knowledge of which can be used to improve subsequent iterations of the PBS model that is the focus of the present study.

\section{Methods}

\section{Participants and Settings}

The study was designed to include a diversity of participants whose lives were compromised due to the presence of serious and chronic problem behaviors. Criteria for participant inclusion were (a) history of serious problem behaviors such as aggression, selfinjury, tantrums, noncompliance, or persistent stereotypy that were documented to negatively affect the person's life for at least 12 months prior to enrollment; (b) absence of medical or legal conditions that might jeopardize data collection due to hospitalization or incarceration; (c) agreement by the individual, family, and/or caregivers, as appropriate, to participate in the study for at least 2 years; and (d) absence of positive behavior support procedures (i.e., functional assessment and assessment-based interventions) for at least 2 years prior to participation. Participants were recruited and enrolled from five geographic areas that were proximate to research programs conducted by the collaborating investigators: (a) Tampa Bay region of Florida; (b) Long Island, New York; (c) Eugene, Oregon; (d) Santa Barbara, California; and (e) Lawrence-Kansas City, Kansas.

The full sample included 30 participants; however, 9 were excluded from the current study because full- or part-year attrition precluded the collection of sufficient data for 2 consecutive years. Of the 9 who were excluded, 7 were individuals who moved permanently from the area or whose lives were disrupted for extended periods of time due to events such as incarceration or a house fire that caused prolonged disarray and transience. The other 2 participants whose data were not included moved temporarily (and were not present during Year 2 of the study) but moved back to the study's vicinity and resumed participation following the 2 nd year. This left a study sample of 21 individuals who had consistent participation during baseline and Years 1 and 2 of the investigation. The participants ranged in age from 3 to 39 years at enrollment and included a variety of diagnostic characteristics. Table 1 shows the demographics of the study sample.

\section{Procedures}

The procedures for the study were carried out in three phases: baseline, in which preintervention data were obtained from multiple sources; initial assessment and implementation of positive behavior support; and ongoing support.

Baseline. Immediately following enrollment and obtaining informed consent, members of the research team obtained copies of all documents pertaining to the participant's functioning, with a focus on relevant data that had been collected within the previous year. Relevant data included standardized test results; notes and archival data (e.g., attendance, discipline, report cards, etc.) from school, 


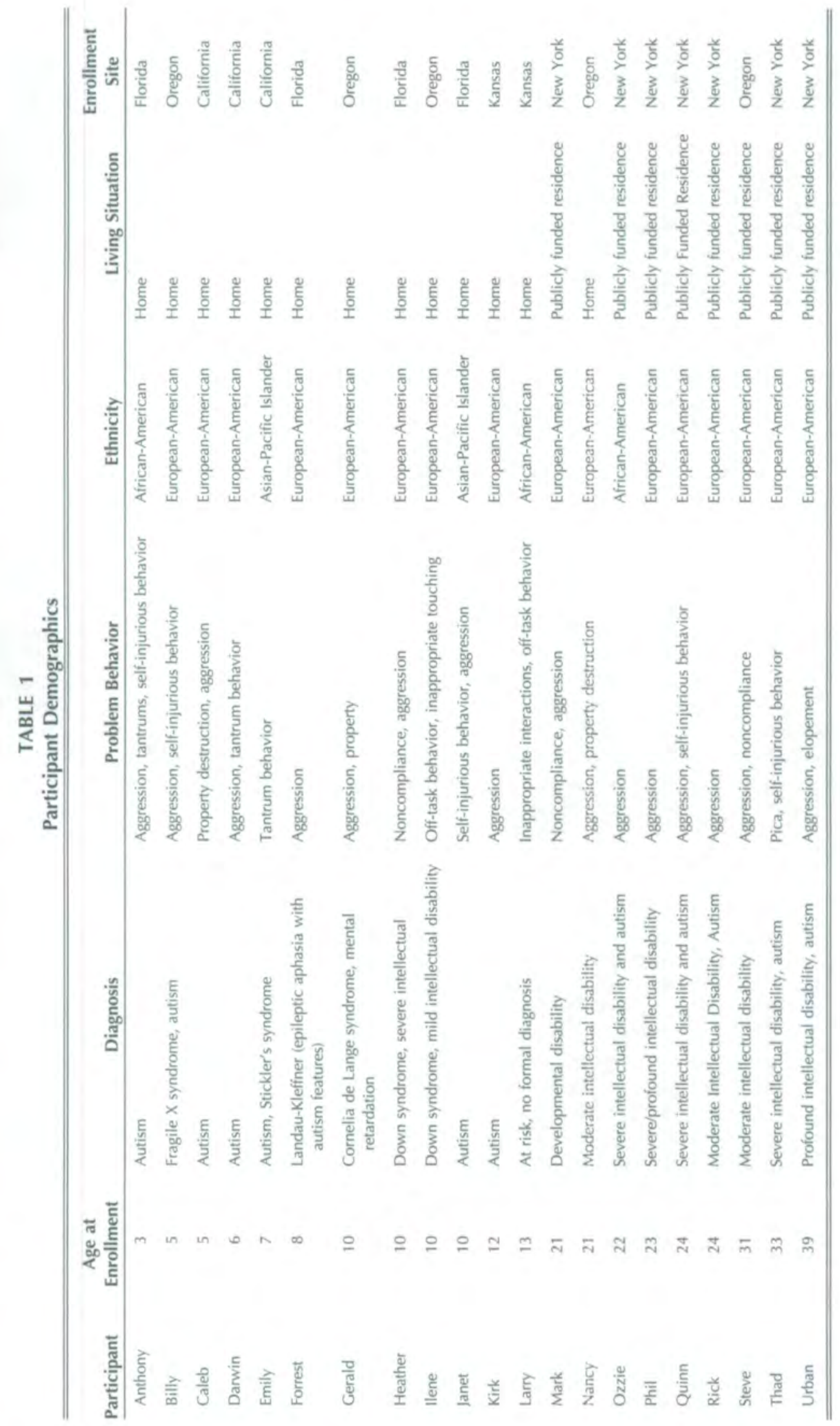

Behavioral Disorders, 35 (4), 259-279 
work, and/or residential files; clinical notes; and, where available, direct observational data obtained by behavioral specialists, school psychologists, and any other consulting professionals.

The researchers also conducted comprehensive, semistructured interviews (e.g., Weisner, Coots, \& Bernheimer, 1997) with parents, caregivers, and support personnel who were directly involved in planning and intervention for the participant. The interviews provided rich background data on the context of the participants' lives, as well as specific information about the most conspicuous and serious problem behaviors and the settings in which these behaviors occurred. Researchers then collected direct observation data on the occurrence of these problem behaviors in the settings identified by the informants. Direct observation data were obtained in multiple settings (at least two and typically between three and five settings). Finally, a full battery of assessments was conducted. These assessments included standardized instruments, structured interviews, and checklists and were individualized on the basis of the participant's age, developmental status, and living circumstances (see the section on measurement for more detail).

Baseline was also the period during which the research team (two to three researchers were identified as primary contacts for each participant and his or her team) established rapport with the participant and his or her parents or principal caregivers. This generally occurred by spending time with the individuals in question, answering questions, and becoming familiar with the preferences, contexts, routines, and circumstances that helped define the participant's life. During this period, the researchers also identified professionals, friends, family members, and other individuals who might serve on planning and implementation team(s) during the intervention phases of the study. The overall baseline phase generally took between 1.5 and 3 months to complete.

Initial assessment and implementation of PBS. The process of initial assessment, development of PBS plans, and implementation of those plans was facilitated by the researchers but carried out by the teams that were established for each participant. The teams varied in composition. Typically they included the participant (if he or she was able to contribute), parents and/or other family members, caregivers, teachers and other school personnel, work and residential supervisors and/or support providers, close friends or extended family members, and other individuals who were involved with the participant's life and behavioral support. Teams were usually composed of three to six individuals, although some were larger. Occasionally, a participant was supported by more than one team. For instance, there might be a team focusing on school concerns and another team focusing on home and community supports; however, in such cases, there was always at least one member who was common to both teams. The researchers served as consultants, facilitators, and coaches. The responsibilities of the team members were to (a) obtain assessment and evaluation information, (b) contribute to the development of PBS support plans, (c) identify and contribute resources that might help in the plan implementation, (d) implement the plan in all relevant settings and assist in promoting the integrity of the plan's implementation, (e) contribute to the collection and analysis of evaluation data, and ( $f$ ) meet periodically to review the plan and update and refine the plan as appropriate.

A first responsibility of the team was to engage in a planning process for building consensus around the participant's strengths, needs, and short- and long-term goals. This process has been described as person-centered planning (Holburn \& Vietze, 2002; Kincaid \& Fox, 2002); however, different planning protocols were followed with different teams depending on the team's preferences. The planning process helped build a unity of purpose and perspective.

The second step was to conduct a functional behavioral assessment (FBA) of the participant's primary problem behaviors (O'Neill et al., 1997; Repp \& Horner, 1999). This step was guided by the researchers, although team members were encouraged to conduct as much of the process independently as possible. The FBA consisted of direct and indirect methods of data collection and resulted in operational definitions of target behaviors and identification of (a) the function of each target behavior, (b) antecedent and setting variables that influenced each behavior, and (c) potential replacement behaviors.

Information from the FBA was then used by the team to build a specific PBS plan for each target behavior and for each relevant setting. Often, the plans would be identical across settings, but occasionally, important 
adjustments would be necessary to fit the characteristics of the setting (Albin, Lucyshyn, Horner, \& Flannery, 1996). The plans contained specific instructions with each plan including definitions of the target behaviors and a delineation of the procedures to follow to develop and reinforce replacement behaviors, provide adequate reinforcement for desirable responding, rearrange the antecedent environment to prevent problem behavior from occurring (Luiselli, 2007), and how to respond to problem behavior if it should occur. The plans also included strategies for obtaining evaluation data to determine if the plan was effective and if it was being implemented as intended. The basic elements of a PBS plan have been described in detail in numerous sources (e.g., Bambara \& Kern, 2005; Carr et al., 1994; Crone \& Horner, 2003; Janney \& Snell, 2008), and the plans in this study were consistent with these published guidelines. An important emphasis, however, with the plans in this study was that they were intended to be comprehensive, covering all relevant settings and times of day.

Once the plans were developed to the satisfaction of the teams, implementation of the plans was initiated. The researchers were present to facilitate, through on-site coaching and modeling, the initial implementation in the majority of settings. However, the researchers quickly faded their presence from the settings (i.e., within 2 to 3 weeks) as their schedules and conflicting responsibilities prevented their continuing presence. The aim of the study was for PBS to be implemented by the natural intervention agents, and therefore, the researchers were never the primary interventionists in any setting. The period of initial assessment and PBS implementation took from 1 to 3 months, depending on the number of settings and teams and the complexity of the assessment data and the PBS plans.

Ongoing support. Following the period of initial implementation, when team members were implementing the plans as intended, the researchers shifted to the next phase. In this phase, the researchers maintained contact with the team, continued to arrange for periodic data collection, and participated in team meetings as requested. On occasion, it was necessary for teams to revise their plans and even collect additional data for an updated FBA. Revisions were made when transitions occurred (e.g., a participant moved to a new classroom, a teacher was replaced) or when new stimuli were introduced that evoked problem behaviors that had not been exhibited for some time (cf. Carr, Levin, et al., 1999). Sometimes teams had to be reconstituted because of major transitions that left important team members unavailable or irrelevant. Ongoing support was provided for all 21 participants for the 2 years covered by this investigation.

\section{Measurement}

A large variety of data were obtained for each participant on an individualized basis. In every case, data were obtained on aspects of the participant's functioning and the participant's life circumstances to provide information on the occurrence of problem behaviors, the extent to which the PBS plans were being implemented, and multiple dimensions of the participant's QOL. However, because of substantial differences in the ages and characteristics of the participants, the specific instruments used to collect data varied across participants. Therefore, each participant's data set constituted an individualized case portiolio. The complete list of data collection instruments and strategies through which the individualized batteries were selected is presented in Table 2. This table displays the name of the instrument, its purpose, and its schedule of administration. As is evident, some instruments were administered at baseline and then annually (e.g., the ecocultural family interview: Weisner et al., 1997), semiannually (e.g., the Child Behavior Checklist [CBCL]: Achenbach, 1991; Achenbach \& Rescorla, 2001), periodically on an as-needed basis (e.g., Functional Behavioral Assessment Interview: O'Neill et al., 1997), or continually (e.g., researchers' journals and contact logs).

For the descriptive analysis, three categories of measures were critical: measures of problem behavior, implementation of PBS plans, and QOL. The column in Table 2 labeled purpose indicates the main category for which a measure was used. One data collection strategy that provided extensive information for all three categories was the researchers' journals and contact logs. These were ongoing narrative records of participant observations, telephone calls, and all other contacts that pertained to the participant's functioning and life circumstances. Researchers maintained these journals on an ongoing basis. 
TABLE 2

Data Collection Instruments Used in the Study

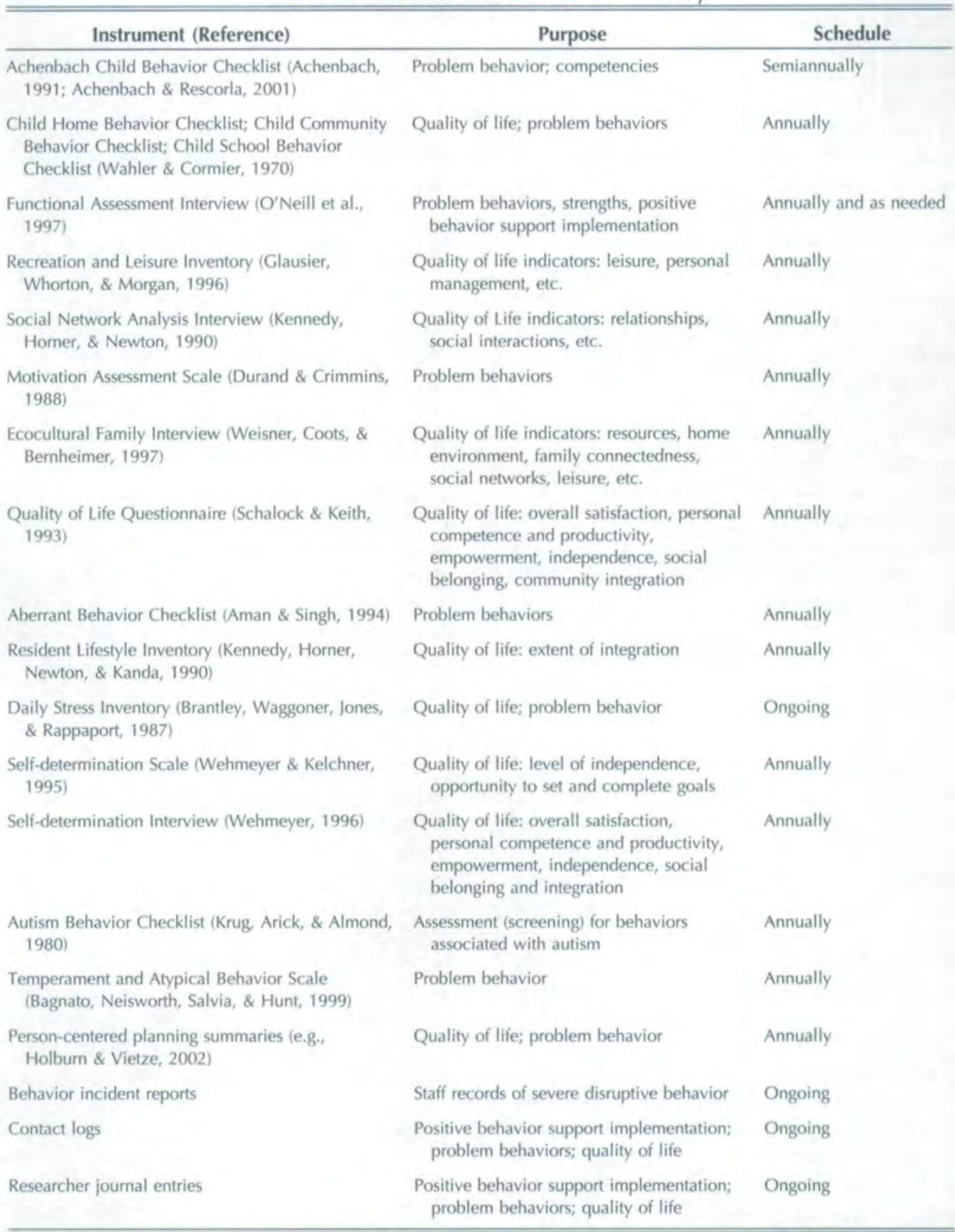

For each participant, multiple types of measures were obtained for each of the dependent variables. For instance, problem behavior was measured with periodic administrations of a standardized instrument (e.g., $\mathrm{CBCL}$ ), direct observations, and notes recorded in the researchers' journals. The multiple and diverse data provided a form of triangulation and a multidimensional perspective on changes occurring in levels of problem behavior and $\mathrm{QOL}$.

\section{Data Summation}

The ideographic nature of the participants' portfolios of data made it impossible to use a single set of instruments to describe changes in variables of interest across the diverse study 
sample. In addition, no single measures were available to reliably evaluate participants' status and changes in terms of QOL or the degree with which the PBS plans were implemented across all relevant settings during all relevant days over extended periods of time. Therefore, a strategy was developed to use rating scales to summarize changes over time for each participant based on the entirety of the participant's data portfolio, with a focus on those instruments that were especially germane to the variable in question (indicated in Table 2). Although we are not aware of a precedent for rating scales being used in the literature to summarize complex data portfolios, such scales have been used frequently for coding complex behavioral phenomena (e.g., Dunlap \& Koegel, 1980).

For each participant, the full data portfolios were divided into three sets: all data that were obtained at baseline, all data for the first full year following PBS implementation, and all data for the second full year following PBS implementation. Then, the data elements in each time period were coded (typically using color markers) to indicate the variable(s) to which the element pertained: either problem behavior, PBS implementation, or one of the dimensions of QOL (see below for these definitions).

For problem behavior and six domains of QOL, scoring instructions and rating scales were developed. Problem behavior and QOL were the two main dependent variables in this study. The instructions specified that raters were to examine the coded baseline information in detail, make notes, and develop a written summary of the participant's functioning during 4 to 6 months prior to the intervention (this period often included weeks or months of file notes accumulated prior to the involvement of the research team). This summary served as the basis from which ratings of change were to be judged. Raters then examined in detail all of the pertinent data elements for the relevant variable for Year 1. After all of these data had been examined, the rater formed a judgment regarding differences between Year 1 and baseline and made a rating accordingly. The 9-point rating scale that applied to changes in problem behavior and each dimension of QOL is shown in Table 3. The scale was made to be applicable to the different dependent variables by replacing the word Situation and the parenthetical references to "behavior/this domain" on the rating scale (see Table 3) with the specific variable being scored (e.g., "problem behavior," "material well-being"). When the rating for Year 1 was complete, the rater examined all of the data elements for Year 2 and repeated the process. Again, the baseline summary was the standard against which Year 2 ratings were formed. That is, ratings for Year 2 indicated changes in the relevant variable from baseline to Year 2 .

The ratings for PBS implementation, a measure of independent variable (intervention) fidelity, were conducted differently in that no baseline data were considered. Instead, raters examined all of the data elements from the portfolios that pertained to the implementation of the PBS plans in the targeted settings and times of day. Raters' judgments were based on the full 12-month period and all settings and contexts. When the data elements for Year 1 were examined, the rater made a judgment of PBS implementation according to the 5-point scale shown in Table 4. When Year 1 ratings were made, the process was repeated for Year 2.

\section{Definitions}

Problem behavior. In examining the data to determine ratings of change in problem behavior, raters were instructed to consider all evidence of problem behavior exhibited by the participant over the designated scoring period (baseline, Year 1, Year 2). Data sources included standardized instruments (e.g., $\mathrm{CBCL}$ ); direct observation of target behaviors; FBAs; interviews with family members, caregivers, and support providers; researchers' journals and log books; and other sources (see Table 2). All problem behaviors were to be considered with the overall rating being based on the topography, duration, frequency, intensity, and circumstances associated with behaviors. The effects of problem behavior on the participant's life were to be considered (e.g., being removed or excluded from activities or opportunities) to reflect the significance of impact.

Quality of life. For the purpose of this investigation, QOL was defined as being composed of a person's status in six life domains. It has been recognized for many years that QOL is a construct that is vital for evaluating a person's life status as well as the effectiveness of interventions designed to improve a person's life circumstances; how- 
TABLE 3

Nine-Point Rating Scale for Scoring Changes in Problem Behavior and Each of the Six Domains of Quality of Life

\begin{tabular}{|c|c|}
\hline Rating Scale & Description \\
\hline 1 & $\begin{array}{l}\text { Situation has deteriorated very substantially relative to baseline. This score represents a very severe decline to } \\
\text { the point that great concern is warranted over this aspect of the person's life. }\end{array}$ \\
\hline 2 & $\begin{array}{l}\text { Situation has deteriorated relative to baseline. The data show clear indications that the person's status in this } \\
\text { domain has worsened and the effect on the person's life is easily discernable. }\end{array}$ \\
\hline 3 & $\begin{array}{l}\text { Situation has worsened somewhat relative to baseline. The indications of decline are evident, but they may be } \\
\text { judged to be minor, possibly temporary, or uneven; there may even be some indications of small } \\
\text { improvements in this area, but on balance, the changes are certainly negative. }\end{array}$ \\
\hline 4 & $\begin{array}{l}\text { Situation has worsened slightly relative to baseline. Changes have occurred and, on balance, they are } \\
\text { regarded as negative, but the changes may be slight, partial, or sporadic. Some improvements in (behaviorl } \\
\text { the domain) may be identified, but as a whole, the changes tilt toward the negative. }\end{array}$ \\
\hline 5 & $\begin{array}{l}\text { No changes relative to baseline. This means that the status in (behavior/this domain) is unchanged from } \\
\text { baseline or that the improvements and deteriorations balance themselves out. }\end{array}$ \\
\hline 6 & $\begin{array}{l}\text { Situation has improved slightly relative to baseline. Changes have occurred and, on balance, they are } \\
\text { regarded as positive, although the changes may be slight, partial, or sporadic. Some declines in (behavior! } \\
\text { the domain) may be identified, but as a whole, the changes tilt toward the positive. }\end{array}$ \\
\hline 7 & $\begin{array}{l}\text { Situation has improved somewhat relative to baseline. The indications of improvement are evident, although } \\
\text { they may be judged to be minor, possibly temporary, or uneven; there may even be some indications of } \\
\text { small declines in (behavior/this domain), but on balance, the changes are certainly positive. }\end{array}$ \\
\hline 8 & $\begin{array}{l}\text { Situation has improved relative to baseline. The data show clear indications that the person's status in } \\
\text { (behavior/this domain) has become better and the effect on the person's life is easily discernable. }\end{array}$ \\
\hline 9 & $\begin{array}{l}\text { Situation has improved very substantially relative to baseline. This score represents a very dramatic } \\
\text { improvement to the point that little or no further improvement could be envisioned. }\end{array}$ \\
\hline
\end{tabular}

ever, it is also elusive and difficult to operationalize (Edgerton, 1990; Landesman, 1986; Schalock, 1990; Taylor \& Bogdan, 1990). Although there have been notable efforts to develop instruments for assessing the global construct of QOL (e.g., Schalock, Keith, Hofman, \& Karan, 1989), there are no tools for reliably assessing the construct with a population as diverse as the one in the current study. Therefore, the approach taken in this investigation followed the recommendations of many scholars and relied on multiple sources of information (e.g., Dennis, Williams, Giangreco, \& Cloninger, 1993) to assess participants' status on core aspects of the QOL construct. Six domains were identified from the literature and defined with sufficient specificity to permit reliable assessments. The six domains were material wellbeing, health and safety, social well-being, emotional/affective well-being, leisure and recreation, and personal well-being. Descriptions of the domains are presented in Table 5 .

TABLE 4

Five-Point Scale for Rating Implementation of Positive Behavior Support (PBS) Plans for Years 1 and 2

\begin{tabular}{|c|c|}
\hline Rating Scale & Description \\
\hline 1 & $\begin{array}{l}\text { PBS not implemented systematically in any environment at all for any appreciable period of time (low } \\
\text { fidelity). }\end{array}$ \\
\hline 2 & $\begin{array}{l}\text { PBS support plan was implemented to some extent, but it was restricted primarily to one environment and } \\
\text { was implemented inconsistently (with questionable integrity and temporarily or sporadically). }\end{array}$ \\
\hline 3 & $\begin{array}{l}\text { PBS support plan was implemented in more than one environment with some effort to be consistent but } \\
\text { without indications of integrity over extended periods of implementation (moderate fidelity). }\end{array}$ \\
\hline 4 & PBS support plan was implemented in multiple environments by multiple agents for extended periods of time. \\
\hline 5 & $\begin{array}{l}\text { PBS support plan was implemented systematically in all relevant environments by multiple intervention } \\
\text { agents with a high level of integrity across the year (high fidelity). }\end{array}$ \\
\hline
\end{tabular}




\begin{tabular}{|c|c|}
\hline Domain & Description \\
\hline Material well-being & $\begin{array}{l}\text { This domain contains information about access to materials or activities that are preferred by the } \\
\text { individual and may enhance the individual's pleasure or ability to function effectively. } \\
\text { Information in this domain may involve personal possessions (e.g., toys, clothes, computer, } \\
\text { automobile, money), living arrangements (e.g., housing), or other indications (e.g., income) } \\
\text { relevant to the person's access to tangible items that are of value to the individual. }\end{array}$ \\
\hline Health and safety & $\begin{array}{l}\text { This domain contains information about the individual's health status that may involve chronic } \\
\text { or acute illnesses or physical impairments, including any changes related to physical well- } \\
\text { being. This would include effects of medications, the presence of seizures, sleep disorders, } \\
\text { and any other physiological manifestations. This domain also assesses safety concerns related } \\
\text { to the individual's daily life, which may involve the emergence or resolution of risks (in the } \\
\text { home or community) to the individual's physical well-being. }\end{array}$ \\
\hline $\begin{array}{l}\text { Social well-being and } \\
\text { interpersonal competence }\end{array}$ & $\begin{array}{l}\text { This domain involves the individual's social network, presence of friends, the perceptions of } \\
\text { peers and others regarding the individual's social interactions, as well as the individual's } \\
\text { capabilities for engaging in social relationships and social commerce. Considerations include } \\
\text { the variety and depth of social activities and contacts as well as skills in the areas of } \\
\text { communication, social interplay, and behavioral adaptation in social contexts. (Problem } \\
\text { behavior per se is not considered here except insofar as it has social implications.) }\end{array}$ \\
\hline $\begin{array}{l}\text { Emotional and affective } \\
\text { well-being }\end{array}$ & $\begin{array}{l}\text { This domain encompasses the individual's personal contentment and sense of attachment and } \\
\text { closeness with family members or other intimates. Affective well-being of the individual is } \\
\text { assessed via outward emotional responses, evidence of happiness, mood, and emotional } \\
\text { stability. Also considered is the closeness of intimate relationships and the security, comfort, } \\
\text { and satisfaction that are derived from these attachments. }\end{array}$ \\
\hline Leisure/recreation & $\begin{array}{l}\text { This domain includes activities the individual engages in to occupy himself or herself for } \\
\text { pleasure. Leisure activities include hobbies, games, reading, watching TV/videos, etc. } \\
\text { Recreation may include activities outside of the house such as sports, going to parks, camping, } \\
\text { arts, movies, going to the beach, and so on. Leisure/recreation may be social or solitary. }\end{array}$ \\
\hline Personal well-being & $\begin{array}{l}\text { Personal well-being includes self-sufficiency and independence, self-determination, and choice } \\
\text { regarding personal belongings, activities, clothing, food, living arrangements, and } \\
\text { relationships. The individual or person may provide input with regard to changes in the } \\
\text { environment (e.g., decorations, room arrangement, etc.), purchase of personal items, and } \\
\text { recreation and leisure activities. This domain also involves levels of autonomy in self-care } \\
\text { (including grooming, hygiene, and dressing) and satisfaction derived from accomplishment } \\
\text { and productivity in the realms of school, work, or domestic activity. This domain may also } \\
\text { include spiritual pursuits as they pertain to personal development and contentment. }\end{array}$ \\
\hline
\end{tabular}

Implementation of PBS. Evaluation of the degree to which PBS was developed and implemented was based on multiple sources of information, especially the researchers' journals and logs. These records were compared with a checklist used by the researchers to assess fidelity: (a) An FBA was completed in which possibly relevant antecedent and maintaining stimuli were identified, (b) the FBA identified all major environments in which problem behavior occurred, (c) direct observations were conducted to confirm hypotheses, (d) PBS support team(s) were assembled and agreed to provide assistance and support, (e) person-centered planning was conducted including descriptions of goals for improved lifestyles, and (f) multicomponent PBS plans were developed and implemented in designated settings. The rating scale for assessing the degree of PBS implementation for Years 1 and 2 is shown in Table 4.

\section{Raters and Interrater Agreement}

Raters for each of the three variables were individuals with multiple years of experience with observing and recording outcomes and implementation of PBS. Raters at each site included researchers who were involved with guiding the PBS implementation as well as individuals (e.g., graduate students) who were not involved with the intervention process.

Before using any of the rating scales for obtaining data for the study, each of the scales was tested for interrater agreement (reliability). Scoring instructions and rating scales were provided to two raters who independently coded and rated the case portfolios for each variable for 2 participants. Agreement was assessed and differences in ratings were used to refine the scoring instructions.

The ratings used for the descriptive analysis, reported in the following Results section, 


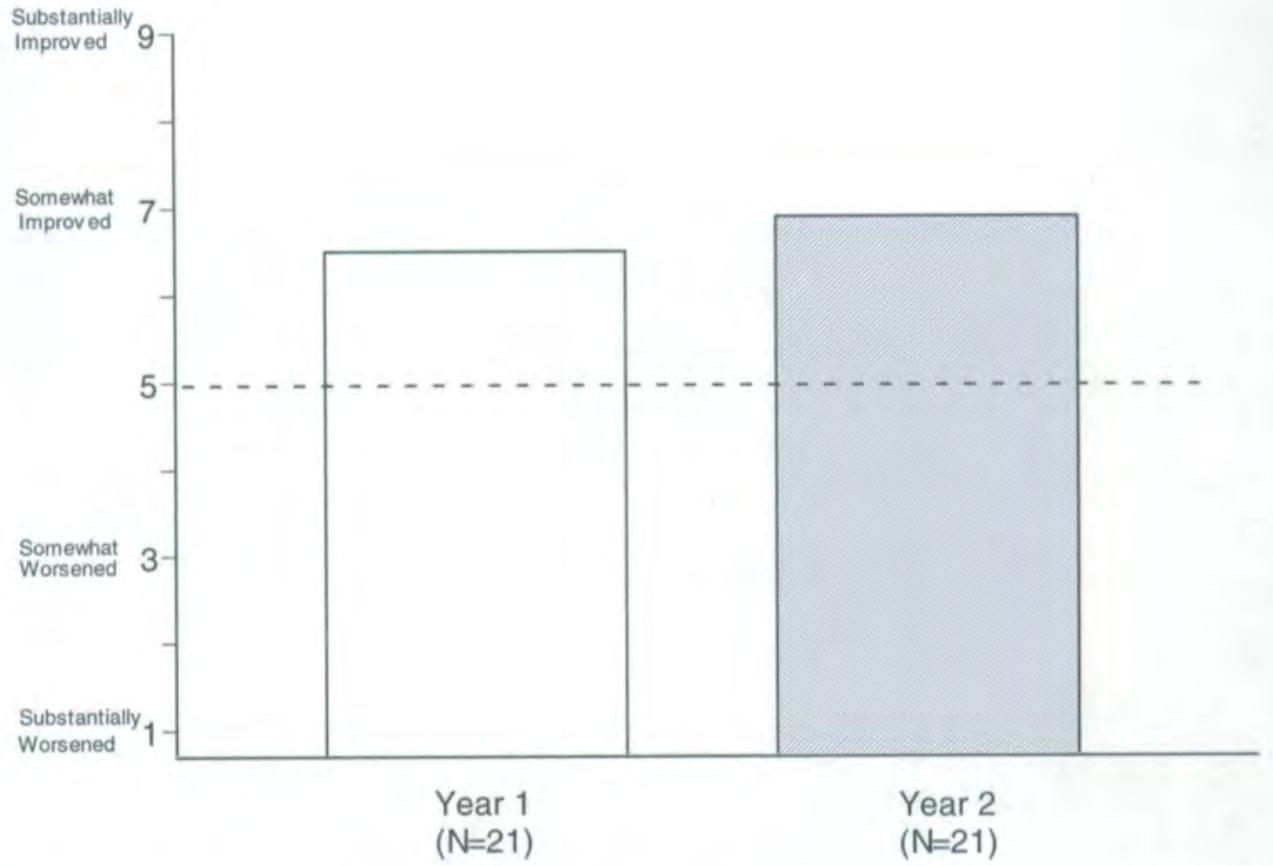

Figure 1. Means of behavior change ratings for participants $(N=21)$ for Years 1 and 2 . The dashed line indicates the level at which no change from baseline was evident. The rating scale is shown in Table 3.

were also evaluated for interrater agreement. Interrater agreement was evaluated for Years 1 and 2 across the three variables, with an agreement being defined as two ratings that were within 1 point of each other. One rater was designated as primary, and it was this rater's scores that were used for the results. Reliability was assessed for behavior change ratings for 20 of the 21 participants, with $100 \%$ agreement across both Year 1 and Year 2. For QOL scoring, interrater agreement was completed for a minimum of 19 of the 21 participants across each of the six domains that were rated for both Year 1 and Year 2. The mean percentage agreement for all participants across all QOL domains for both Year 1 and Year 2 was $96 \%$. The range across individual domains was $52 \%$ to $100 \%$ agreement for Year 1 and $89 \%$ to $100 \%$ for Year 2. Interrater agreement for PBS implementation was completed for 15 of the 21 participants in Year 1 and 14 of 21 participants in Year 2. Both years yielded $100 \%$ agreement across raters.

\section{Results}

The data from the study are presented in three sections: Problem Behavior, Quality of Life, and PBS Implementation.

\section{Problem Behavior}

Figure 1 shows the mean behavior change rating scores for the 21 participants for Years 1 and 2 . As is evident, the ratings show some improvement for the participants' average score for Year $1(M=6.5)$ and further improvement for Year $2(M=6.9)$. Referring to the anchor points for the rating scale (Table 3), these scores indicate modest improvement in the participants' problem behavior relative to baseline, with improvement generally maintaining over the 2 years of the study. Table 6 provides the individual ratings for the 21 participants for both years. Inspection of these data for Year 1 indicate that 17 of the participants showed improvement with respect to their problem behavior, 2 were rated as showing no change, and 2 were considered to have gotten worse. For Year 2, 18 participants were rated as having improved relative to baseline, 1 was rated as showing no change, and 2 were rated as having their problem behavior worsen. For the most part, the ratings fell in the middle to upper-middle ranges of the scale; that is, the vast majority of scores were in the 6 to 8 range, with very few scores at the extremes. There were no scores of 1 or 2 and only one score of 3 and one of 9. 
TABLE 6

Participant Mean Behavior Change Ratings for Year 1 and Year 2

\begin{tabular}{lcc}
\hline \hline & \multicolumn{2}{c}{ Mean Behavior Change Rating } \\
\cline { 2 - 3 } Participant & Year 1 & Year 2 \\
\hline Anthony & 7 & 6 \\
Billy & 6 & 7 \\
Caleb & 7 & 7 \\
Darwin & 7 & 8 \\
Emily & 8 & 8 \\
Forrest & 8 & 7 \\
Gerald & 7 & 8 \\
Heather & 7 & 6 \\
Hene & 7 & 7 \\
Janet & 8 & 8 \\
Kirk & 6 & 7 \\
Larry & 6 & 5 \\
Mark & 5 & 8 \\
Nancy & 6 & 8 \\
Ozzie & 4 & 8 \\
Phil & 3 & 6 \\
Quinn & 7 & 4 \\
Rick & 7 & 5 \\
Steve & 8 & 9 \\
Thad & 5 & 7 \\
Urban & 7 & 4 \\
\hline \hline
\end{tabular}

\section{Quality of Life}

Quality of life was defined in this investigation as a construct composed of six domains. To arrive at an overall index of change in QOL, the domain scores were averaged for each participant for each year. To portray changes in the study population, a mean was calculated of these averages. These data are presented in Figure 2. Here, the data indicate that the average rating of changes in overall QOL for the 21 participants was 6.16 for Year 1 and 6.57 for Year 2. These mean ratings indicate a perceived improvement during Year 1 with a slight additional improvement in Year 2. Table 7 shows the mean of the averaged QOL scores for each participant. This table reveals that ratings for 20 of the 21 participants in both Years 1 and 2 showed improvements in overall QOL relative to baseline.

The means across participants for each domain are presented in Figure 3, with the corresponding ratings for individual partici- pants shown in Table 8 . The patterns here are generally consistent, with improvements being evident during Year 1 and some additional improvement for Year 2. It is important to note that data on emotional/affective well-being were not able to be provided for 2 participants for Year 2 due to insufficient information in the case portfolios, so the means for this variable are based on an $n$ of 19 .

To better examine the relationship between the PBS intervention and QOL, a multivariate analysis of variance (MANOVA; using an $\alpha$ of $p<.05$ ) was conducted to address three questions: (a) Are QOL scores statistically different from Year 1 to Year 2? (b) Do differences in QOL scores from Year 1 to Year 2 depend on perceived change in problem behavior? and (c) Do differences in QOL scores from Year 1 to Year 2 vary across the six QOL domains? The main effect of year describes how students' QOL scores changed from Year 1 to Year 2. The MANOVA results indicate a small but statistically significant increase in QOL scores between Year 1 and Year 2, $F(1,16)=5.317, p=.035$. The next step in analysis examined the interaction effect between year and problem behavior (increase, no change, decrease). The MANOVA results indicate that there was a statistically significant interaction between year and change in problem behavior, $F(1,16)=5.80, p=.013$, suggesting that the QOL increase from Year 1 to Year 2 depended on perceived improvement in problem behavior. The final analysis examined the interaction between year and QOL domain to determine if improved level of QOL varied by domain. The MANOVA results did not indicate a statistically significant interaction, $f(3.79,60.59)=.76, p=.55$, suggesting that patterns of QOL were consistent across the six QOL domains. Taken together, these results indicate that the reported improvement in QOL from Year 1 to Year 2 was (a) statistically significant, (b) related to decreases in perceived problem behavior, and (c) consistent across the six QOL domains.

\section{Implementation of PBS}

In addition to the principal dependent variables of change in problem behavior and QOL, summary data were obtained on the degree to which PBS plans were implemented across relevant settings. Case portfolios were examined and summary ratings of implemen- 


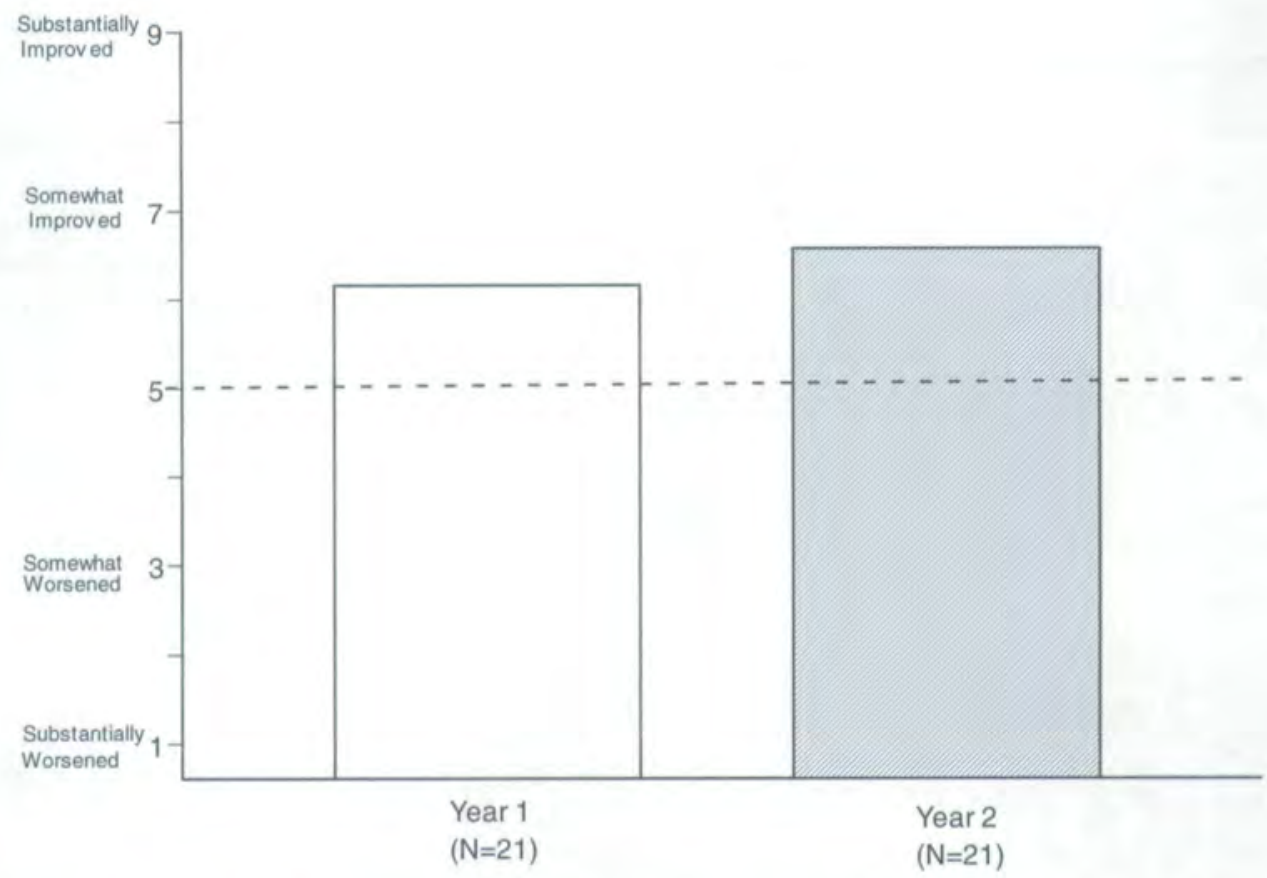

Figure 2. Means of quality of life ratings, averaged across all domains, for participants $(\mathrm{N}=21$ ) for Years 1 and 2. The dashed line indicates the level at which no change from baseline was evident. The rating scale is shown in Table 3.

tation fidelity for Years 1 and 2 were based on the 5-point scale shown in Table 4. The mean ratings for each year are depicted in Figure 4, and individual ratings are shown in Table 9. Data on implementation were not available for 1 participant, so the data provided are for only 20 of the participants. The means on this variable were 3.4 for Year 1 and 3.57 for Year 2 , indicating that raters perceived the PBS plans as being "implemented in more than one environment with some effort to be consistent, but without indications of integrity over extended periods of implementation."

\section{Discussion}

Data of the type yielded by this investigation are novel in the field of PBS and, indeed, in the more general area of intervention for problem behavior. There have been no previous efforts to use multiple measures to evaluate overall changes in problem behavior and QOL across participants' entire life for years at a time. The present study represented an attempt to ascertain whether participants' lives improved or worsened along the dimensions of problem behavior and six domains of QOL. Rating scales, which were demonstrated to be reliable, indicated that, relative to baseline, the vast majority of participants exhibited improvements in the key dependent variables, although the improvements were generally modest and there were occasional exceptions. Another major finding of the study pertained to the implementation of the positive behavior support plans. The data indicated that the plans were implemented as intended by natural intervention agents, although raters judged that the implementation was realized with less than ideal breadth and integrity.

An encouraging aspect of the data is that efforts to deliver comprehensive PBS, consisting of multicomponent interventions carried out by natural intervention agents across all relevant life settings over protracted periods of time, was associated with consistent reductions in problem behavior as well as improvements in QOL across multiple domains. Previous data have shown favorable effects of PBS on problem behavior; however, the majority of these data have been obtained over brief periods of time, in limited contexts, and generally with atypical intervention agents (Carr, Horner, et al., 1999; Dunlap, Clarke, \& Steiner, 1999). The few studies that have spanned more than 1 year of intervention have data collection that is still primarily restricted 
TABLE 7

Participant Mean Quality-of-Life Change Ratings for Year 1 and Year 2

\begin{tabular}{lcc}
\hline & \multicolumn{2}{c}{ Mean Behavior Change Rating } \\
\cline { 2 - 3 } Participant & Year 1 & Year 2 \\
\hline Anthony & 5.7 & 6.7 \\
Billy & 5.7 & 6 \\
Caleb & 6.5 & 7.7 \\
Darwin & 6.2 & 7.5 \\
Emily & 7.2 & 8.2 \\
Forrest & 7.2 & 7 \\
Gerald & 5.8 & 6.5 \\
Heather & 6.8 & 5.3 \\
Hene & 5.2 & 6 \\
Janet & 6.5 & 6.5 \\
Kirk & 6 & 7.7 \\
Larry & 6.3 & 5.7 \\
Mark & 3.8 & 7 \\
Nancy & 5.5 & 6.33 \\
Ozzie & 5.3 & 6.8 \\
Phil & 7 & 7.2 \\
Quinn & 6.3 & 6.5 \\
Rick & 6.7 & 6.3 \\
Steve & 7.3 & 6.5 \\
\hline Thad & 6.5 \\
Urban & 7.3 \\
\hline \hline & & \\
\hline
\end{tabular}

to direct observations and caregiver reports in specific targeted contexts (e.g., Carr, Levin, et al., 1999; Feldman et al., 2002). In the current study, we explicitly arranged for the dependent variable (ratings) to be as comprehensive as possible, covering all waking hours of a participant's life. Our interest was in seeing what would happen to the level of problem behavior subsequent to a broad intervention. The ratings were encouraging in that change in problem behavior was viewed as reflecting general improvement over the course of Year 1 , with further improvement being seen, on average, over the course of Year 2 .

The reductions in problem behavior, although clinically meaningful, were modest in magnitude, particularly when compared with the reductions reported in many reports of previous research (Carr, Horner, et al., 1999). However, it is important to appreciate that the vast majority of previous research involved analyses conducted over short peri- ods of time with substantial controls and in atypical contexts. A message from the current results is that stable, long-term reductions in problem behavior accruing from PBS in natural circumstances are not likely to be dramatic. This outcome is likely due to innumerable real-life factors that can interfere with or dilute intervention plans, such as competing priorities of families, staffing changes, health issues, occasional crises, resource shortages, and so on. An implication is that PBS plans may be more effective if they explicitly address these common perturbations by arranging for ongoing family and staff support, regular monitoring of intervention integrity, and periodic review of the elements of the intervention plan with scheduled assessments of such features as contextual fit and behavioral function and relevant antecedents. Still, when considering the current data, it may well be the case that for individuals with chronic problem behaviors (a criterion for participation), steady and ongoing reductions that continue over extended periods of time are probably more important than reductions of great magnitude, especially if such initial reductions are not shown to maintain. As has been noted by several authors (e.g., Turnbull \& Turnbull, 1990), behavior support is viewed best as a long-term endeavor rather than a short-term undertaking - a marathon and not a sprint.

The data on QOL show patterns similar to the data on problem behavior. That is, the majority of participants showed improvements in all six domains of QOL, and these improvements were evident over the course of both Years 1 and 2. Although improvements in QOL are considered one of the essential goals of PBS, very few studies have actually defined and measured it as a dependent variable (e.g. Feldman et al., 2002). This is understandable as few studies have been conducted longitudinally or with as comprehensive an approach as the current investigation. Instead, the majority of studies on PBS have examined the efficacy of individual components of PBS, and it is unlikely that implementation of a single component would significantly affect $\mathrm{QOL}$. The magnitude of improvement in QOL documented in the present study also merits comment. For instance, on a scale of 1 to 9 , the degree of improvement observed was in the range of 6 to 7 (moderate) rather than at the highest levels possible. Interestingly, literature from the field of positive psychology suggests that it may be naïve to assume that any 


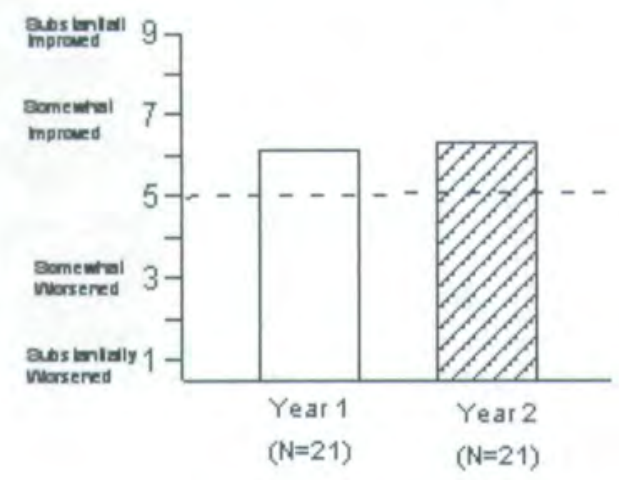

Social Well-Being Domain

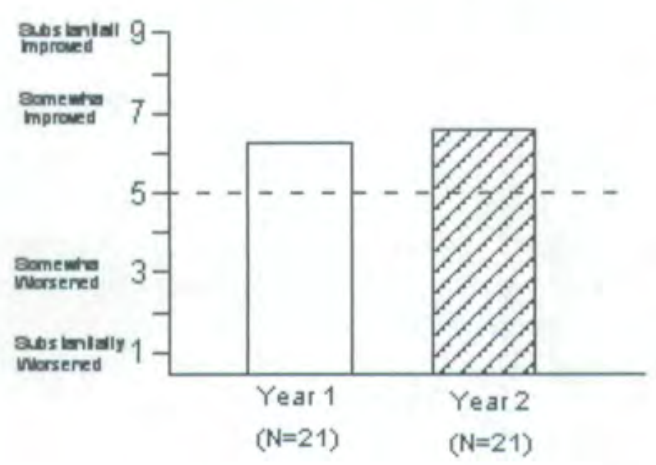

Leisure/Recreation Domain

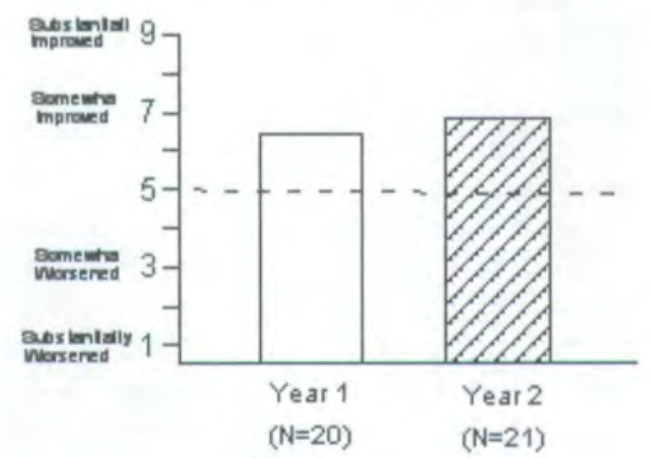

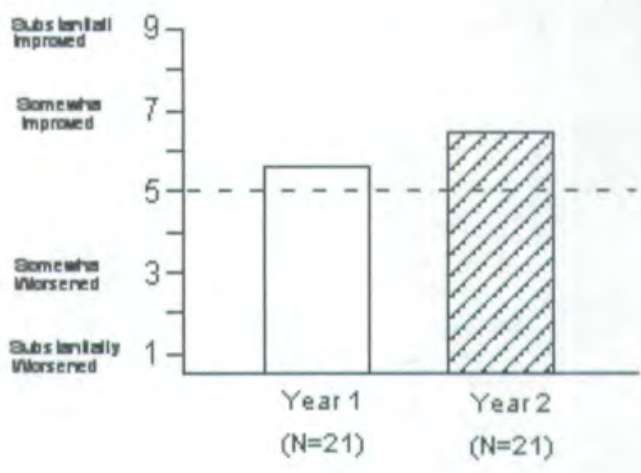

Emotional/Affective

Well-Being Domain

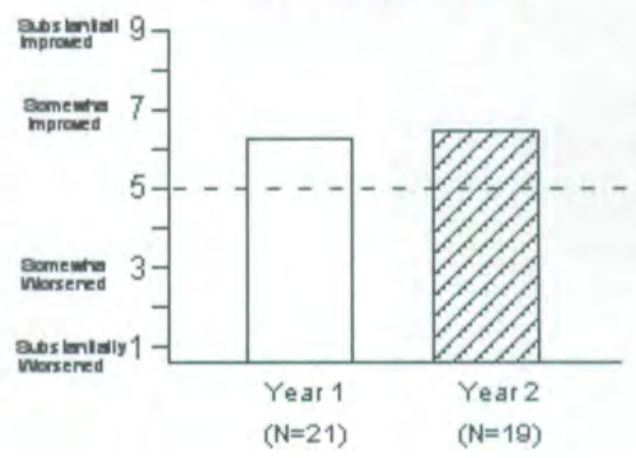

Personal Well-Being Domain

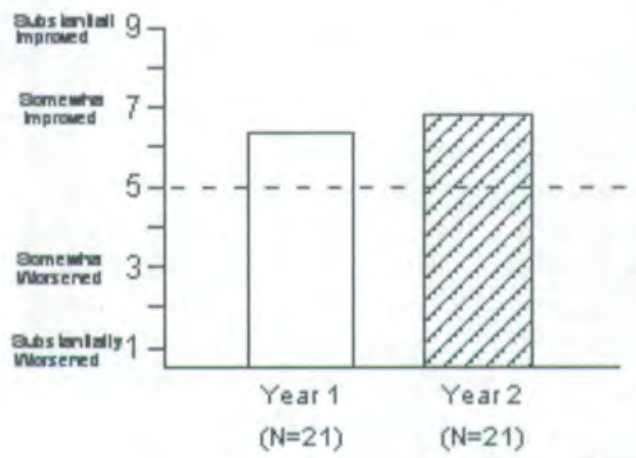

Figure 3. Means of each quality-of-life domain for participants $(\mathrm{N}=21)$ for Years 1 and 2. The dashed lines indicate the level at which no change from baseline was evident. The rating scale is shown in Table 3.

intervention, however well conceived, would result in optimal or near optimal QOL (i.e., a score of 9) for any group of individuals. Specifically, data collected worldwide on subjective well-being (a key indicator of $\mathrm{QOL})$ show that most people who are alive today experience a moderate level of life satisfaction (Diener, 2000). In this sense, the QOL outcomes observed in the present study could plausibly be viewed as normative.

The data on PBS implementation (intervention integrity) show that it was possible for 


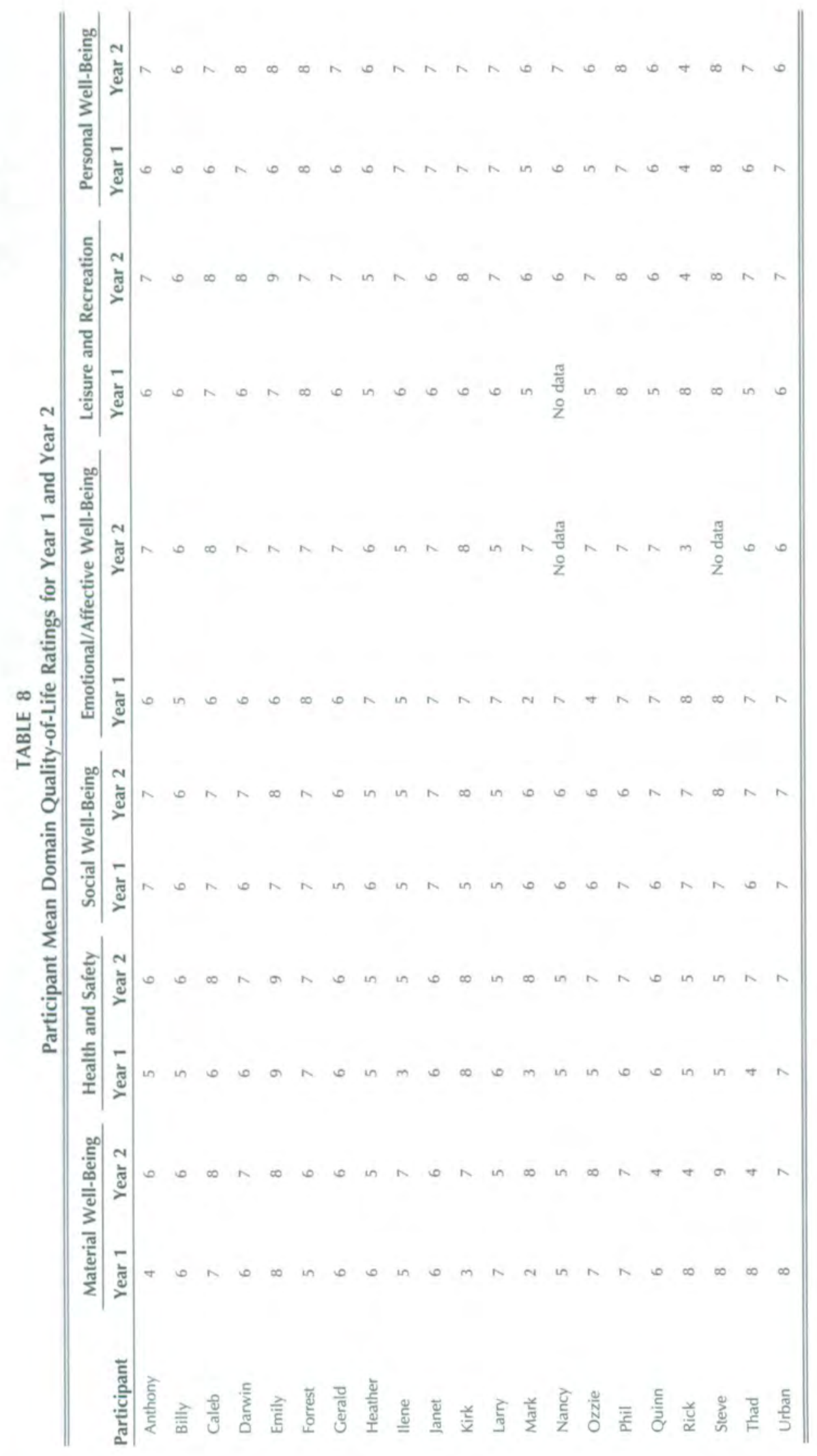




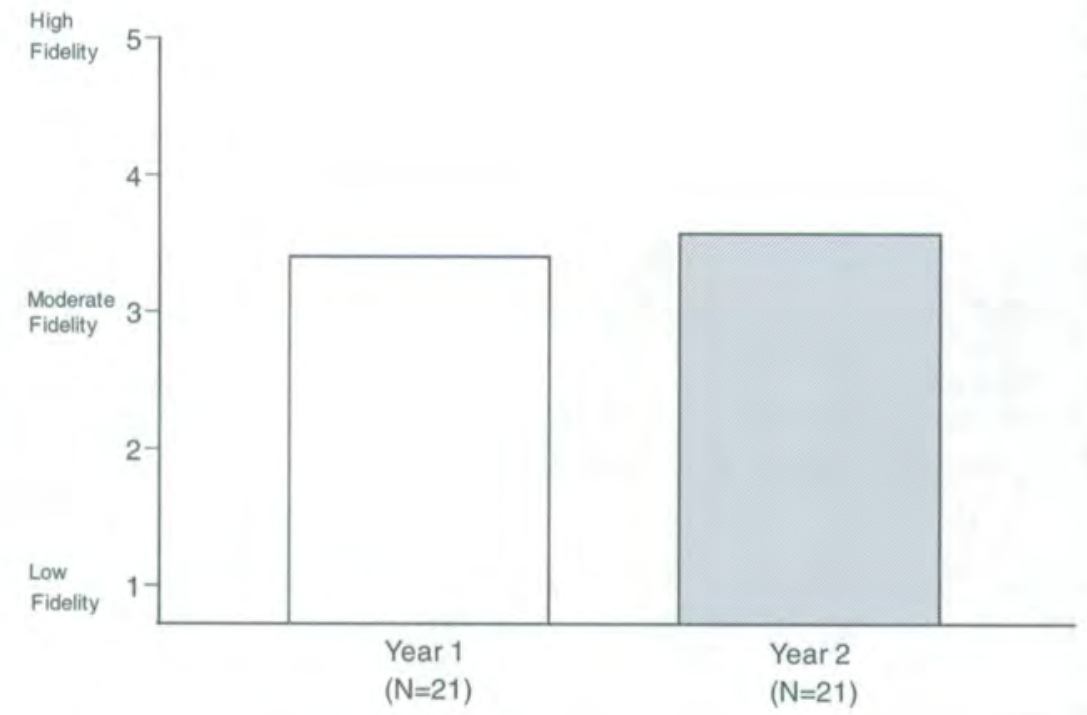

Figure 4. Mean ratings of positive behavior support implementation for Years 1 and 2. The rating scale is shown in Table 4.

TABLE 9

Mean Ratings for Positive Behavior Support (PBS) Implementation

\begin{tabular}{|c|c|c|}
\hline \multirow[b]{2}{*}{ Participant } & \multicolumn{2}{|c|}{ PBS Implementation Rating } \\
\hline & Year 1 & Year 2 \\
\hline Anthony & 3 & 4 \\
\hline Billy & 4 & 3 \\
\hline Caleb & 4 & 5 \\
\hline Darwin & 4 & 4 \\
\hline Emily & 5 & 5 \\
\hline Forrest & 3 & 2 \\
\hline Gerald & 5 & 4 \\
\hline Heather & 3 & 3 \\
\hline Ilene & 4 & 5 \\
\hline Janet & 3 & 4 \\
\hline Kirk & 4 & 4 \\
\hline Larry & 3 & 4 \\
\hline Mark & 2 & 3 \\
\hline Nancy & 4 & 4 \\
\hline Ozzie & 3 & 3 \\
\hline Phil & 3 & 3 \\
\hline Quinn & 4 & 5 \\
\hline Rick & 3 & 1 \\
\hline Steve & 4 & 4 \\
\hline Thad & 3 & 3 \\
\hline Urban & 4 & 3 \\
\hline
\end{tabular}

intervention agents to implement comprehensive PBS in multiple environments with some degree of consistency, although intensive effort was difficult to sustain across environments and over time. The modest levels of integrity reported in this study contrast markedly with the very high levels of integrity described in many of the short-term studies that comprise previously published research (Carr, Horner, et al., 1999). However, the current study was conducted only with natural intervention agents in round-the-clock, natural contexts, which are circumstances that are distinctly unlike previous investigations. The levels of PBS implementation seen in the current study raise many questions related to sustainability and systems features that might elevate the quality and durability of intervention. For example, as discussed previously, it is possible that concerted efforts in family and staff support, monitoring of integrity, and the provision of pertinent resources could improve PBS implementation sufficiently to bring about further improvements in problem behavior and QOL. A research effort focused on these possibilities would be extremely useful in analyzing variables related to implementation and increased sustainability (Fixsen, Naoom, Blase, Friedman, \& Wallace, 2005).

The present investigation was unique in many respects and, as such, carries a number of important limitations. First, the use of rating scales to synthesize very large amounts of data over entire years is both unusual and challen- 
ging. The variables of interest (e.g., problem behavior) tend to fluctuate a great deal over a year's period of time as well as by environment, context, and time of day. The data that were entered into the ratings were diverse and, depending on the instrument, collected on a periodic basis. Raters acknowledged that the task of determining a single rating from a year of diverse data was difficult. Although the high levels of interrater reliability are encouraging, it is acknowledged that the meaning of the ratings beyond the anchors indicated on Tables 3 and 4 are open to multiple interpretations. In future studies, it would be useful to collect data and use summary rating scales in such a way (e.g., by completely independent raters) that a total absence of bias could be guaranteed. However, given the levels of interrater agreement, the use of raters who were not involved with the interventions, and the considerable scatter and modest gains reflected in the ratings, it seems unlikely that the results were influenced in a significant way by the participation of researchers in the scoring of the data.

A second limitation that must be acknowledged is that the connection between the PBS interventions and the dependent variables is correlational. No causal relationship should be inferred. In a study as broad as this one, there are innumerable variables that could affect all of the dependent variables, and it is not known how extensive the impact of the PBS plans might have been. Although our experience and previous research on PBS suggest that the PBS implementation might well have affected levels of problem behavior, the design of the study did not rule out the presence of alternative influences. Future studies of these phenomena should rely on single-subject (e.g., multiple baseline) or randomized control group designs.

Caution is also necessary in interpreting the QOL ratings. Although an ideal scenario of PBS implementation would have the comprehensive supports leading to a vast spread of beneficial influence, there are an inestimable number of events that could also have an impact, with some perhaps more likely to affect particular QOL domains. For instance, a change in a family's income would likely affect material well-being more readily than a PBS plan. Even though the consistency of the findings across participants may plausibly implicate PBS as an effective approach, the design of the study permits no causal attributions.
Although the current data are correlational, the associations are clear enough to warrant further examination of the observed phenomena. In particular, a reasonable next step for future research would be to conduct a formal experiment with a comparison group to establish the effectiveness of the PBS intervention with more rigorous controls. In addition, experimental and component analyses of the processes of PBS implementation would be useful to address important questions such as the amount of follow-up support required to maintain implementation integrity and the functional value of the various elements of the independent variable. Future research should also address the systems variables relevant to the integrity and sustainability of implementation (e.g., Fixsen et al., 2005).

Research such as the current investigation, involving multiple years of data collection and intervention provided by natural agents in natural circumstances, presents numerous challenges. The challenges are amplified when the research questions address broad constructs such as QOL and overall level of problem behavior. However, it is urgent that such studies be carried out because they reflect, much more closely than typical shortterm analog analyses, the essential processes and desired outcomes of interventions such as PBS. The results of the current study are encouraging in that steady improvements were seen for the vast majority of participants, but more importantly, they are heuristic. The data highlight the point that longitudinal outcomes are apt to be modest compared with results in previous reports, and they raise crucial questions about PBS implementation and how such integrity might be enhanced across relevant settings and over extensive periods of time. Focused research addressing these questions could produce a substantial impact in our efforts to improve outcomes for all people affected by serious and chronic problem behavior.

\section{REFERENCES}

Achenbach, T. M. (1991). Integrative guide for the $1991 \mathrm{CBCL} / 4-18, Y S R$, and TRF profiles. Burlington: University of Vermont, Department of Psychiatry.

Achenbach, T. M., \& Rescorla, L. A. (2001). Manual for ASEBA school-age forms \& profiles. Burlington: University of Vermont, Research Center for Children, Youth, \& Families.

Albin, R. W., Lucyshyn, J. M., Horner, R. H., \& Flannery, K. B. (1996). Contextual fit for 
behavior support plans: A model for "goodness of fit." In L. Koegel, R. Koegel, \& G. Dunlap (Eds.), Positive behavioral support: Including people with difficult behavior in the community (pp. 81-98). Baltimore: Paul H. Brookes.

Aman, M. G., \& Singh, N. N. (1994). Aberrant Behavior Checklist-Community. New York: Slosson Educational Publications.

Bagnato, S. J., Neisworth, J. T., Salvia, J., \& Hunt, F. (1999). Temperament and Atypical Behavior Scale (TABS). Baltimore: Paul H. Brookes.

Bambara, L., \& Kern, L. (Eds.). (2005). Individualized supports for students with problem behaviors: Designing positive behavior plans. New York: Guilford Press.

Brantley, P., Waggoner, C. D., Jones, G. N., \& Rappaport, N. B. (1987). A daily stress inventory: Development, reliability, and validity. Journal of Behavioral Medicine, 10, 61-73.

Carr, E. G., Dunlap, G., Horner, R. H., Koegel, R. L., Turnbull, A. P., Sailor, W., et al. (2002). Positive behavior support: Evolution of an applied science. Journal of Positive Behavior Interventions, 4, 4-16.

Carr, E. G., \& Durand, V. M. (1985). Reducing behavior problems through functional communication training. Journal of Applied Behavior Analysis, 18, 111-126.

Carr, E. G., Horner, R. H., Turnbull, A. P., Marquis, J., Magito-McLaughlin, D., McAtee, M. L., et al. (1999). Positive behavior support for people with developmental disabilities: $A$ research synthesis. Washington, DC: American Association on Mental Retardation.

Carr, E. G., Levin, L., McConnachie, G., Carlson, J. I., Kemp, D. C., \& Smith, C. E. (1994). Communication-based interventions for problem behavior: $A$ user's guide for producing behavior change. Baltimore: Brookes.

Carr, E. G., Levin, L., McConnachie, G., Carlson, J. I., Kemp, D. C., Smith, C. E., et al. (1999). Comprehensive multisituational intervention for problem behavior in the community: Long term maintenance and social validation. Journal of Positive Behavior Interventions, 1, 5-25.

Crone, D. A., \& Horner, R. H. (2003), Building positive behavior support systems in schools: Functional behavioral assessment. New York: Guilford Press.

Dennis, R. E., Williams, W., Giangreco, M. F., \& Cloninger, C. J. (1993). Quality of life as context for planning and evaluation of services for people with disabilities. Exceptional Children, 59, 499-512.

Diener, E. (2000). Subjective well-being: The science of happiness and a proposal for a national index. American Psychologist, 55, 34-43.

Dunlap, G., \& Carr, E. G. (2007). Positive behavior support and developmental disabilities: A summary and analysis of research. In S. L. Odom, R. H. Horner, M. Snell \& J. Blacher (Eds.), Handbook of developmental disabilities (pp. 469-482). New York: Guilford.

Dunlap, G., Carr, E. G., Horner, R. H., Zarcone, J., \& Schwartz, I. S. (2008). Positive behavior support and applied behavior analysis: A familial alliance. Behavior Modification, 32, 682-698.

Dunlap, G., Clarke, S., \& Steiner, M. (1999). Intervention research in behavioral and developmental disabilities: 1980 to 1997. Journal of Positive Behavior Interventions, 1, 170-180.

Dunlap, G., \& Hieneman, M. (2005). Positive behavior support. In G. Sugai \& R. Horner (Eds.), Encyclopedia of behavior modification and cognitive behavior therapy (Vol. 3): Educational applications (pp. 1421-1428). Thousand Oaks, CA: Sage.

Dunlap, G., \& Koegel, R. L. (1980). Motivating autistic children through stimulus variation. Journal of Applied Behavior Analysis, 13, 619-627.

Durand, V. M., \& Crimmins, D. B. (1988). Identifying the variables maintaining self-injurious behavior. Journal of Autism and Developmental Disorders, 18, 99-117.

Edgerton, R. B. (1990). Quality of life from a longitudinal research perspective. In R. L. Schalock (Ed.), Quality of life perspectives and issues (pp. 149-160). Washington, DC: American Association on Mental Retardation.

Feldman, M. A., Condillac, R. A., Tough, S., Hunt, S., \& Griffiths, D. (2002). Effectiveness of community positive behavioral intervention for persons with developmental disabilities and severe behavior disorders. Behavior Therapy, 33, 377-398.

Fixsen, D. L., Naoom, S. F., Blase, K. A., Friedman, R. M., \& Wallace, F. (2005). Implementation research: A synthesis of the literature. Tampa: Florida Mental Heath Institute, University of South Florida.

Glausier, S. R., Whorton, J. E., \& Morgan, R. (1996). A recreation and leisure inventory: Development and application. Rural Goals 2000: Building programs that work. Hattiesburg, MS: Institute for Disabilities Studies.

Halle, J., Bambara, L. M., \& Reichle, J. (2005). Teaching alternative skills. In L. Bambara, \& L. Kern (Eds.), Individualized supports for students with problem behaviors: Designing positive behavior plans (pp. 237-274). New York: Guilford Press.

Holburn, S., \& Vietze, P. M. (Eds.). (2002). Personcentered planning: Research, practice, and future directions. Baltimore: Paul $\mathrm{H}$. Brookes.

Hughes, C., Hwang, B., Kim, J.-H., Eisenman, L. T., \& Killian, D. J. (1995). Quality of life in applied research: A review and analysis of empirical measures. American Journal on Mental Retardation, 99, 623-641.

Janney, R., \& Snell, M. E. (2008). Behavioral support (2nd ed.). Baltimore: Paul H. Brookes.

Kennedy, C. H., Horner, R. H., \& Newton, J. S. (1990). The social networks and activity patterns 
of adults with severe disabilities: A correlational analysis. Journal of the Association for Persons with Severe Handicaps, 15, 86-90.

Kennedy, C. H., Horner, R. H., Newton, J. S., \& Kanda, E. (1990). Measuring the activity patterns of adults with severe disabilities using the Resident Lifestyle Inventory. Journal of the Association for Persons with Severe Disabilities, 15, 79-85.

Kincaid, D., \& Fox, L. (2002). Person-centered planning and positive behavior support. In S. Holburn \& P. M. Vietze (Eds.), Person-centered planning. Research, practice, and future directions (pp. 29-50). Baltimore: Paul H. Brookes.

Krug, D. A, Arik, J., \& Almond, P. (1980). Behavior checklist for identifying severely handicapped individuals with high levels of autistic behavior. Journal of Child Psychology and Psychiatry, 21, 221-229.

Landesman, S. (1986). Quality of life and personal life satisfaction: Definition and measurement issues. Mental Retardation, 24, 141-143.

Lucyshyn, J. M., Albin, R. W., Horner, R. H., Mann, J. C., Mann, J. A., \& Wadsworth, G. (2007). Family implementation of positive behavior support for a child with autism: Longitudinal, single-case experimental and descriptive replication and extension. Journal of Positive Behavior Interventions, 9, 131-150.

Luiselli, J. K. (Ed.). (2007). Antecedent intervention: Recent developments in community focused behavior support. Baltimore: Paul H. Brookes.

O'Neill, R. E., Horner, R. H., Albin, R. W., Storey, K., Sprague, J. R., \& Newton, J. S. (1997). Functional assessment of problem behavior: A practical assessment guide. Pacific Grove, CA: Brooks/Cole.

Repp, A. C., \& Horner, R. H. (Eds.). (1999). Functional analysis of problem behavior: From effective assessment to effective support. Belmont, CA: Wadsworth.

Sailor, W., Dunlap, G., Sugai, G., \& Horner, R. (Eds.). (2009). Handbook of positive behavior support. New York: Springer.

Schalock, R. L. (1990). Attempts to conceptualize and measure quality of life. In R. L. Schalock (Ed.), Quality of life perspectives and issues (pp. 141-148), Washington, DC: American Association on Mental Retardation.

Schalock, R. L., \& Keith, K. D. (1993). Quality of life questionnaire. Worthington, $\mathrm{OH}$ : IDS.

Schalock, R. L., Keith, K. D., Hoffman, K., \& Karan, O. C. (1989). Quality of life: Its measurement and use. Mental Retardation, 27, 25-31.

Taylor, S. J., \& Bogdan, R. (1990). Quality of life and the individual's perspective. In R. L. Schalock (Ed.), Quality of life perspectives and issues (pp. 27-40). Washington, DC: American Association on Mental Retardation.

Turnbull, A. P., \& Turnbull, H. R. (1990). A tale about lifestyle changes: Comments on "Toward a technology of 'nonaversive' behavioral support." Journal of the Association for Persons With Severe Handicaps, 15, 142-144.

Wahler, R. G., \& Cormier, W. H. (1970). The ecological interview: A first step in out-patient child behavior. Journal of Behavior Therapy, 1 , 279-289.

Wehmeyer, M. L. (1996). A self-report measure of self-determination for adolescents with cognitive disabilities. Education and Training in Mental Retardation and Developmental Disabilities, 31, 282-293.

Wehmeyer, M. L., \& Kelchner, K. (1995). The Arc's self-determination scale. Arlington, TX: Arc National Headquarters.

Weisner, T. S., Coots, J., \& Bernheimer, L. (1997). The ecocultural family interview manual. Los Angeles, CA: UCLA Center for Culture and Health.

\section{AUTHORS' NOTE}

This investigation was supported by the Research and Training Center on Positive Behavior Support funded by the National Institute on Disability Rehabilitation and Research of the U.S. Department of Education (Grant No. H133B980005). The authors wish to acknowledge the following for assistance with data collection and implementation of the PBS protocols: Dan Baker, Amy McCart, James Sanborn, Linda Eisman, Christine Schulte, Michelle Duda, Michelle Marrill, Jody Gail, Stephanie Johnston, Lisa Littke, Amy Smolka, Miriam Steiner, and Kathy Wefel. Finally, the authors wish to dedicate this article to the memory of Edward G. (Ted) Carr, whose contributions to PBS and to this study were immense.

Address correspondence to Glen Dunlap, Ph.D. Division of Applied Research and Educational Support, Department of Child and Family Studies, FMHI, University of South Florida, 2778 Mayberry Drive, Reno, NV 89509; E-mail: glendunlap@sbcglobal.net.

MANUSCRIPT

Initial Acceptance: 12/21/09

Final Acceptance: 1/28/10 